\title{
INDIVIDUAL MEAN-VARIANCE RELATION AND STOCK-LEVEL INVESTOR SENTIMENT
}

\author{
Jun Sik KIM ${ }^{1}$, Da-Hea KIM², Sung Won $\mathrm{SEO}^{3}$ \\ ${ }^{1}$ Division of International Trade, Incheon National University, 119 Academy-ro, \\ Yeonsu-gu, Incheon 22012, Republic of Korea \\ ${ }^{2}$ SKK Business school, Sungkyunkwan University, Sungkyunkwan-ro, Jongno-gu, \\ Seoul 03063, Republic of Korea \\ ${ }^{3}$ School of Business, Ajou University, 206 Worldcup-ro, \\ Yeongtong-gu Suwon 16499, Republic of Korea \\ E-mails: ${ }^{1}$ junsici@inu.ac.kr; ${ }^{2}$ daheakim@skku.edu; \\ ${ }^{3}$ seosw@ajou.ac.kr (corresponding author)
}

Received 18 January 2016; accepted 21 October 2016

\begin{abstract}
This research studies the effect of stock-level investor sentiment on individual stock returns' mean-variance relation. Using unique buy and sell volume data of retail investors in Korean stock market, we find that a positive mean-variance relation is undermined among high-sentiment stocks, but holds among low-sentiment stocks. We adopt buy-sell imbalances of retail investors for individual stocks as a measure of stock-level investor sentiment. Further, our findings provide empirical evidence of a strong riskreturn trade-off among stocks with low retail concentration (e.g., large capitalization, high-priced, and growth stocks). Existing research only analyzes market-wide investor sentiment. However, we study the effect of stock-level investor sentiment on individual stock returns. Therefore, our findings suggest novel implications about the investment strategy that the stock-level investor sentiment is important when constructing portfolios based on variance.
\end{abstract}

Keywords: investor sentiment, mean-variance relation, risk-return trade-off, conditional variance, buy-sell imbalance, individual stock markets.

JEL Classification: G12, G14, G15.

\section{Introduction}

Many researchers and practitioners have shown interest in investor sentiment (ISENT). Baker and Wurgler $(2006,2007)$ study the direct effect of market-wide ISENT on future stock returns ${ }^{1}$. Massa and Yadav (2015) further show that the investor sentiment affects the strategy and performance of mutual funds. Lately, finance studies also focus on

\footnotetext{
${ }^{1}$ Da et al. (2015) also report the consistent results based on a new measure of investor sentiment. They construct a new measure of investor sentiment using the volume of queries related to household concerns (e.g., "recession," "unemployment," and "bankruptcy").
} 
the indirect effect of ISENT on stock markets (Ho, Hung 2009; Yu, Yuan 2011; Baker et al. 2012; Stambaugh et al. 2012; Danbolt et al. 2015; Shen et al. 2016). Kumar and Lee (2006) suggest that the systematic component of retail investors' stock trading can explain the return co-movements of stocks. Furthermore, they suggest that the buy-sell imbalance (BSI) of retail investors has an explanatory power over future stock market returns. Their findings are inconsistent with classical research, which suggests that uninformed investors cannot have an impact on stock prices, because rational investors trade stocks in the opposite direction until they take the full arbitrage. In this regard, we further investigate the effect of stock-level ISENT on future stock returns.

This paper studies the effect of stock-level ISENT on the risk-return trade-off of an individual stock. Although individual stocks face different degrees of ISENT at the same time, prior literature does not study stock-level measures of ISENT among individual stocks. Therefore, we further study that sentiment investors' cluster together in specific individual stocks. We find that ISENT does not equally affect all, but some, individual stocks. The BSI in Kumar and Lee (2006) is our measure of ISENT for each individual stock. Our findings suggest empirical evidence of a positive risk-return relation among stocks with low retail investors' BSI, as the classical financial theories predict. Low (high) BSI implies that the retail investors sell more (less) stock than they buy.

We hypothesize that where retail investors' BSI is low, stocks show a positive riskreturn relation as the classic financial theories predict. However, stocks with high retail investors' BSI show negative risk-return relations. BSI indicates the demand of retail investors for an individual stock. We consider it as the driving force behind the riskreturn trade-off for three reasons: first, retail investors face high short-sale constraints. In this regard, individuals' negative opinions about future stock prices cannot immediately reflect on their stock trading. Consequently, the realized volatility does not correctly measure the true value of volatility (Karlsson et al. 2009). In the case of the stock market index, individuals can trade short-selling alternatives, such as taking a long position in index put options and inverse index funds. However, individuals cannot have an effective way of taking short positions in the individual stocks of the Korean stock market ${ }^{2}$. Accordingly, the short-sale constraints of retail investors have a greater impact on the risk-return relation of individual stocks than on that of the market index. Second, individuals who lack of trading experience are likely to be sentiment and irrational investors. Consequently, many retail investors cannot precisely estimate future risk. This irrational trading of retail investors affects the relation between risk and risk compensation. Retail investors' trading has a dominant effect on the risk-return relation, especially in the Korean stock market (Hong, Lee 2011). Finally, retail investors' investment strategy does not fully reflect the risk-return trade-off, because their stock trading pattern is subject to personal bias. Individuals are willing to pay a cost to avoid certain stocks because of their cognitive bias (Odean 1998; Barber, Odean 2000, 2008). Accordingly, the risk-return trade-off collapses by retail investors' cognitive bias, although we assume that individuals can correctly estimate future risk.

\footnotetext{
${ }^{2}$ The Korean options market has 20 individual stocks with individual stock options, which is about $0.95 \%$ of the 2101 listed stocks in the Korean stock market.
} 
The contributions of our research are as follows. First, we try to shed additional light on the ISENT literature. To the best of our knowledge, this research is the first to study the effect of stock-level ISENT on individual stock returns. Prior literature focuses only on market-wide ISENT. As Kumar and Lee (2006) describe, U.S. data on BSI are very rare and available only for short time periods. Furthermore, they do not cover all retail investors in the U.S. However, we collect buy and sell trading data of all listed companies in the Korean stock market for a sufficiently long period, from 2000 to 2014. These unique and valuable buy and sell trading data allow us to investigate the effect of stocklevel ISENT on individual stock prices. Second, this research has implications for the literature on the risk-return relation. Prior empirical studies report a negative risk-return relation, which suggests that the riskier the stock, the less the compensation (Brandt, Kang 2004; Li et al. 2005) although financial theories propose a positive relation. Our findings are consistent with the classical model, where a positive risk-return relation is observed when rational investors' trading exerts a stronger effect on the individual stocks than sentiment investors' trading does.

The rest of the paper is organized as follows. Section 1 describes the literature on the mean-variance relation (MVR). Section 2 introduces our main variables including the ISENT measure and conditional variance (CV) and describes the data. Section 3 explains empirical results. Final section concludes our research.

\section{Literature review}

Volatility is an important risk factor among financial assets, and the MVR in financial markets, such as stock market, bond market, and exchange market, has been investigated in previous literature. Merton (1980) finds a positive relation between the expected return (mean) and risk (variance) in the stock market over time. This positive relation is consistent with high risk-high return in theories of rational asset pricing. However, empirically, this relation is not always observed in stock market. In the prior literature, variant MVR is explained by business cycle (Fama, French 1989) and variance in risk aversion (Campbell, Cochrane 1999).

In general, theories predict that high risk yields high rewards, suggesting a positive MVR. However, a number of empirical research papers find the opposite relation between volatility and returns (Brandt, Kang 2004; Lettau, Ludvigson 2010). Many researchers investigate the reason behind this anomaly. Yu and Yuan (2011) find that future stock market returns are positively related to the conditional market variance during high-sentiment periods and negatively related during other periods. In other words, they explain that the negative risk-return trade-off is caused by market-wide ISENT. Yu and Yuan (2011) note that their stock-level analysis is limited in that they use only a market-wide ISENT index. Antoniou et al. (2016) also show that high beta stock are over-valued during high sentiment periods, and traditional beta are observed during other periods. Our research extends the line of literature, using a stock-level ISENT index, to investigate the cross-sectional effect of ISENT on the risk-return relation of individual stocks. Furthermore, we provide evidence that the positive risk-return relation is relatively stronger among stocks with low retail investor concentration (e.g., large capitalization, high-priced, and growth stocks). 


\section{Methodology}

\subsection{Stock-level investor sentiment}

Kumar and Lee (2006) show that ISENT is caused by stock trading induced by noninformative stock trading. Furthermore, they demonstrate that a part of retail investors' stock trading is based on non-informative stock trading. Similarly, we assume that cognitive bias can explain some, but not all, stock trading by retail investors. We employ the BSI of individual stocks as a measure of stock-level ISENT because, among the various sentiment indices, only the BSI can function as a stock-level index. The following equation is stock-level sentiment index:

$$
B S I_{i, t}=\frac{\sum_{j=1}^{D_{t}}\left(V B_{i, j, t}-V S_{i, j, t}\right)}{\sum_{j=1}^{D_{t}}\left(V B_{i, j, t}+V S_{i, j, t}\right)},
$$

where $B S I_{i, t}$ is the BSI for stock $i$ in month $t, D_{t}$ is the number of days in month $t, V B_{i, j, t}$ is the retail investors' buy volume of stock $i$ on day $j$ of month $t$, and $V S_{i, j, t}$ is the retail investors' sell volume of stock $i$ on day $j$ of month $t$.

\subsection{Conditional variances}

To evaluate the effect of stock-level ISENT on the mean-variance relation, we employ two volatility models in the study: GARCH $(1,1)$ and asymmetric $\operatorname{GARCH}(1,1)^{3}$.

\subsubsection{GARCH}

The GARCH model is introduced by Bollerslev (1986). In this study, we use GARCH $(1,1)$, which estimates the monthly CV for stock $i$ in month $t+1$, as follows with daily returns:

$$
\begin{gathered}
r_{i, t+1}=\mu_{i}+\varepsilon_{i, t+1}, \text { where } \varepsilon_{i, t+1} \mid I_{t+1} \sim N\left(0, \sigma_{i, t+1}^{2}\right) ; \\
\sigma_{i, t+1}^{2}=\alpha_{i, G}+\beta_{i, G} \varepsilon_{i, t}^{2}+\gamma_{i, G} \sigma_{i, t}^{2},
\end{gathered}
$$

where $r_{i, t}$ is the return of stock $i$ at day $t, \mu_{i}$ is the conditional mean of the stock $i$ 's daily return, $\sigma_{i, t}$ is the daily return volatility of stock $i$ at day $t, I_{t}$ is an information set at day $t$, $N(a, b)$ is the normal distribution with mean $a$ and variance $b$, and $\varepsilon_{i, t}$ is the daily return innovation of the stock $i$ at day $t$ defined as the difference between the stock $i$ 's daily return and the conditional mean of stock $i$ 's daily return.

\subsubsection{Asymmetric GARCH}

The asymmetric GARCH model is suggested by Glosten et al. (1993). The asymmetric GARCH model allows for different shocks of positive and negative return innovations on return volatility. We employ the asymmetric GARCH $(1,1)$ which models the daily estimator of $\mathrm{CV}$ for stock $i$ as:

$$
r_{i, t+1}=\mu_{i}+\varepsilon_{i, t+1}, \text { where } \varepsilon_{i, t+1} \mid I_{t+1} \sim N\left(0, \sigma_{i, t+1}^{2}\right) ;
$$

\footnotetext{
${ }^{3}$ There are some recent studies using GARCH models (Abad, Robles 2014; Ghysels et al. 2014; Kinnunen 2014).
} 


$$
\sigma_{i, t+1}^{2}=\alpha_{i, A}+\beta_{i, A} \varepsilon_{i, t}^{2}+\gamma_{i, A} d_{i, t} \varepsilon_{i, t}^{2}+\theta_{i, A} \sigma_{i, t}^{2},
$$

where $d_{i, t}$ is a dummy variable, the value of which is one when $\varepsilon_{i, t}$ is negative, and other

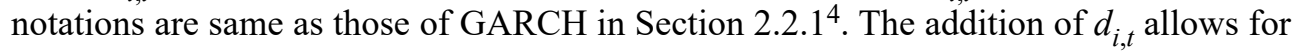
different effects of positive and negative innovations in returns on return volatility. If $\gamma_{i, A}$ is positively (negatively) significant, the negative returns innovations have significantly more (less) influence on return volatility than the positive returns innovations ${ }^{5}$.

\subsubsection{Monthly conditional variance}

We construct the monthly $\mathrm{CV}$ to study the relation between risk and return based on the monthly horizon. Thus, Equation (6) shows the risk of individual stocks in each month as a measure of the monthly $\mathrm{CV}$ to investigate individual stocks:

$$
\operatorname{Var}_{t}\left(R_{i, t+1}\right)=E_{t}\left(\sum_{d=1}^{22} \sigma_{i, t+d}^{2}\right) .
$$

While the unconditional variance is defined as the variance without any information and is the same for the whole sample period, the conditional variance is defined as the variance estimated by the conditional information, such as historical return data of the individual stocks, and is time-varying. Thus, our variances estimated by GARCH and asymmetric GARCH are included in the conditional variance, because we estimate the variance on month $t+1$ based on conditional information on month $t$.

Following Yu and Yuan (2011), we adopt the CV of stocks in month as Equation (6). To get the up-to-date information about firms' risk, we adopt the monthly $\mathrm{CV}$ using daily returns within the month. In this regards, Equation (6) shows that the CV of stock $i$ in month $t+1$ is calculated by the linear sum of the $\mathrm{CV}$ of stock $i$ in days, as a measure of risk in month $t+1$. The previous literature (Engle 2001; Becker et al. 2009; Corsi 2009) suggests that the variance in month $t$ is defined as the linear sum of the daily variances during 22 trading days (business days), included in month $t$, because there are usually 22 trading days in a month. According to the previous research, we also choose 22 trading days per month to construct monthly $\mathrm{CV}$. The $\mathrm{CV}$ of stock $i$ in days of month $t+1$ is estimated by GARCH and asymmetric GARCH based on information in month $t$. The risk of stock return is measured by the $\mathrm{CV}$ of stock return in Equations (3) (GARCH) and (5) (asymmetric GARCH).

\subsection{Data and summary statistics}

In this subsection, we describe the summary statistics of key variables such as excess return, variance as a measure of risk, BSI of retail investors, dummy variable of ISENT in individual stocks, and Fama and French's three-factors (FF3). Our sample period starts

\footnotetext{
${ }^{4}$ We obtain the daily estimator of CV at day $t$, with GARCH $(1,1)$ and asymmetric GARCH $(1,1)$ utilizing the daily returns from day $t-252$ to day $t-1$ (assuming 252 trading days in one year).

${ }^{5}$ For the brevity of the paper, the parameter estimates for GARCH $(1,1)$ and asymmetric GARCH $(1,1)$ are available upon request.
} 
from 2000 to 2014, because buy and sell volumes of retail investors are available from 2000. We exclude an observation if it does not hold for one of our key variables. Excess return is the monthly stock return subtracted by the risk free rate (CD91). The ISENT dummy $\left(D_{i, t}\right)$ is assigned 1 if the BSI of retail investors is greater than zero and zero otherwise. Excess market return is defined as the market return minus the risk free rate and is the monthly return of KOSPI200 subtracted by the risk free rate (CD91). Fama and French (1992) design an asset-pricing model using three factors based on market beta (the return sensitivity to market returns), firms' size, and book-to-market equity. They also show evidence that small firms and high book-to-market firms perform better. HML stands for high-minus-low book-to-market ratio stocks, which is one of FF3 (Fama, French 1992). SMB stands for small-minus-big capitalization, which is another of FF3. Table 1 reports the summary statistics of key variables.

Table 1 . Summary statistics of key variables

\begin{tabular}{lccccc}
\hline \multicolumn{1}{c}{ Variable } & Obs & Mean & Std. dev. & Min & Max \\
\hline Excess return $^{1}$ & 206035 & 0.014 & 0.195 & -0.947 & 8.768 \\
\hline CV of GARCH $(1,1)^{\prime}$ & 206035 & 0.034 & 0.033 & 0.00004 & 0.737 \\
\hline CV of asymmetric GARCH $(1,1)$ & 206035 & 0.034 & 0.033 & 0.00004 & 0.623 \\
\hline BSI of retail investors & 206035 & -0.026 & 0.170 & -1.000 & 1.000 \\
\hline$D_{i, t}$ & 206035 & 0.355 & 0.478 & 0.000 & 1.000 \\
\hline Excess market return & 206035 & 0.003 & 0.064 & -0.215 & 0.226 \\
\hline Monthly stock market return & 206035 & 0.006 & 0.064 & -0.210 & 0.231 \\
\hline HML & 206035 & 0.011 & 0.041 & -0.193 & 0.178 \\
\hline SMB & 206035 & 0.002 & 0.052 & -0.141 & 0.463 \\
\hline
\end{tabular}

Notes: Our sample period is from 2000 to 2014; ${ }^{1}$ CD91 data is obtained from Economic Statistics System of The Bank of Korea (ecos.bok.or.kr).

Figure 1 displays the time-series of yearly means of BSI for individual stocks and shows that BSI plummets in the financial crisis. Thus, BSI effectively reflects the effect of the financial crisis. The BSI also increases again in 2009. It is because the financial crisis started in the U.S. and many of European countries are also largely affected. However, it didn't directly affect the fundamental of Korean stock market in the long-term perspectives; therefore, Figure 1 also presents that the ISENT in Korea get back to the normal level in 2009. 


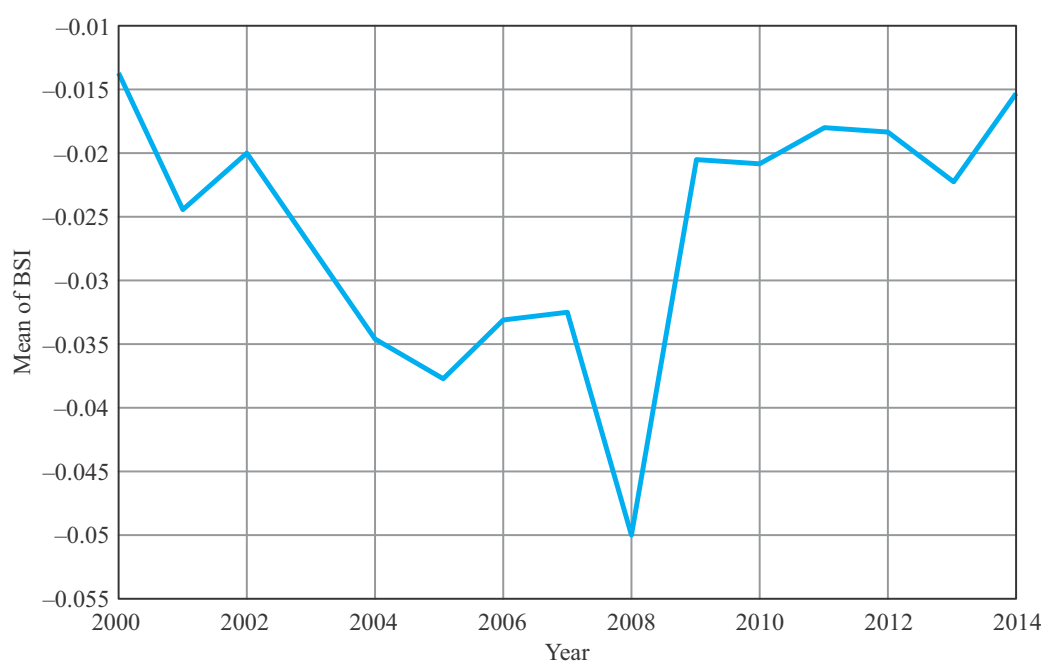

Fig. 1. Time-series of yearly BSI means for the period from 2000 to 2014

\subsection{Regression model}

To gauge the effect of the stock-level ISENT on the relation between return and CV, we employ the following two-regime regression model ${ }^{6}$ :

$$
\begin{aligned}
& R_{i, t+1}^{e}=\alpha_{1}+\alpha_{2} D_{i, t}+\beta_{1} \operatorname{Var}_{t}\left(R_{i, t+1}\right)+\beta_{2} D_{i, t} \times \operatorname{Var}_{t}\left(R_{i, t+1}\right)+\beta_{m}\left(R_{m k t, t}-R_{f, t}\right)+ \\
& \beta_{S M B} S M B_{t}+\beta_{H M L} H M L_{t}+\varepsilon_{i, t},
\end{aligned}
$$

where $R_{i, t+1}^{e}$ is the excess return of stock $i$ for month $t+1, \operatorname{Var}_{t}\left(R_{i, t+1}\right)$ denotes the risk of stock $i$, measured by the $\mathrm{CV}$ of individual stock return for month $t+1, D_{i, t}$ is a dummy variable the value of which is one when BSI of stock $i$ is greater than zero for month $t$. The regression model incorporates that the coefficient estimate on variance among high sentiment firms is different from the one among the low sentiment firms. We expect that the coefficient estimate on the interaction term is negatively significant.

To consider the effect of the other time-varying risk on the MVR, we additionally control for FF3 to consider the effect of the other time-varying risk on the MVR. $R_{f, t}$ is the risk-free rate, and $R_{m k t, t}$ is the market return for month $t$. Excess market return, SMB, and HML are included in FF3.

\section{Empirical analysis}

\subsection{Individual mean-variance relation with stock-level investor sentiment}

This subsection examines whether the ISENT for an individual stock influences the relation between its return and $\mathrm{CV}$ in. In addition, we control for FF3 to consider the effect of the other time-varying risk on the MVR.

\footnotetext{
${ }^{6}$ Following Yu and Yuan (2011), we design the regression model. For the robust regression results, we adjust the effect of heteroscedasticity on the $t$-statistics.
} 
Table 2. Individual MVR with CV of GARCH $(1,1)$

\begin{tabular}{lcccc}
\hline & $(1)$ & $(2)$ & $(3)$ & $(4)$ \\
\hline $\operatorname{Var}_{t}\left(R_{i, t+1}\right)$ & 0.010 & $0.109^{* * *}$ & 0.002 & $0.085^{* *}$ \\
& $(0.38)$ & $(2.76)$ & $(0.09)$ & $(2.25)$ \\
\hline$D_{i, t} \times \operatorname{Var}_{t}\left(R_{i, t+1}\right)$ & & $-0.237^{* * *}$ & & $-0.200^{* * *}$ \\
& & $(-4.69)$ & & $(-4.11)$ \\
\hline$D_{i, t}$ & & 0.002 & & $0.004^{* * *}$ \\
& & $(1.30)$ & & $(2.76)$ \\
\hline$R_{m k t, t}-R_{f, t}$ & & & $1.000^{* * *}$ & $0.999^{* * *}$ \\
& & & $(129.58)$ & $(129.62)$ \\
\hline HML & & & $0.291 * * *$ & $0.292^{* * *}$ \\
& & & $(19.79)$ & $(19.82)$ \\
\hline SMB & & & $0.900^{* * *}$ & $0.899^{* * *}$ \\
& & & $(61.61)$ & $(61.97)$ \\
\hline Constant & $(16.70)$ & $(10.64)$ & $(7.11)$ & $(3.47)$ \\
\hline Observations & 206035 & 206035 & 206035 & 206035 \\
\hline $\mathrm{R}^{2}$ & 0.0000 & 0.0006 & 0.1315 & 0.1318 \\
\hline
\end{tabular}

Notes: Heteroscedasticity-consistent $t$-statistics are reported in parentheses. ${ }^{* *}, * *$, and $*$ denote significance at the $1 \%, 5 \%$, and $10 \%$ levels.

Table 3. Individual MVR with CV of asymmetric GARCH $(1,1)$

\begin{tabular}{lcccc}
\hline & $(1)$ & $(2)$ & $(3)$ & $(4)$ \\
\hline $\operatorname{Var}_{t}\left(R_{i, t+1}\right)$ & 0.013 & $0.109^{* *}$ & 0.009 & $0.091^{* *}$ \\
& $(0.45)$ & $(2.47)$ & $(0.33)$ & $(2.15)$ \\
\hline$D_{i, t} \times \operatorname{Var}_{t}\left(R_{i, t+1}\right)$ & & $-0.229^{* * *}$ & & $-0.198^{* * *}$ \\
& & $(-4.22)$ & & $(-3.79)$ \\
\hline$D_{i, t}$ & 0.002 & & $0.004^{* *}$ \\
& & $(1.00)$ & & $(2.48)$ \\
\hline$R_{m k t, t}-R_{f, t}$ & & $1.000^{* * *}$ & $0.999^{* * *}$ \\
& & & $(129.53)$ & $(129.56)$ \\
\hline HML & & & $0.291^{* * *}$ & $0.292^{* * *}$ \\
& & & $(19.82)$ & $(19.86)$ \\
\hline SMB & & & $0.900^{* * *}$ & $0.899^{* * *}$ \\
& & & $(61.72)$ & $(62.16)$ \\
\hline Constant & $0.013 * * *$ & $0.012^{* * *}$ & $0.006^{* * *}$ & $0.004 * * *$ \\
& $(15.13)$ & $(9.53)$ & $(6.28)$ & $(2.98)$ \\
\hline Observations & 206035 & 206035 & 206035 & 206035 \\
\hline $\mathrm{R}^{2}$ & 0.0000 & 0.0006 & 0.1315 & 0.1318 \\
\hline
\end{tabular}

Notes: Heteroscedasticity-consistent $t$-statistics are reported in parentheses. ***, **, and $*$ denote significance at the $1 \%, 5 \%$, and $10 \%$ levels. 
Tables 2 and 3 report the coefficient estimates and $t$-statistics for the two-regime retail ISENT equation with CVs of GARCH $(1,1)$ and asymmetric GARCH $(1,1)$, respectively. In column (1) of Table 2 , the coefficient estimate for the CV of GARCH $(1,1)$ is 0.010 with a $t$-statistic of 0.38 . In column (2), we add the dummy variable of BSI to the regression model to adjust the effect of retail ISENT on subsequent monthly individual stock returns. While we find a significantly positive MVR for stocks with low retail ISENT, the MVR is weakened for stocks with high retail ISENT. This suggests that firms with high ISENT are subject to the sentiment investors who are inexperienced and undermine the risk-return trade-off. Consequently, the sentiment traders weaken the positive MVRs of high sentiment firms just as the classical theories expect. However, firms with low ISENT are less subject to the sentiment traders; therefore, we observe the positive MVRs which are consistent with the asset-pricing theories. After controlling for FF3, the effect of retail ISENT on the individual MVR is still sustained. The results with the $\mathrm{CV}$ of asymmetric GARCH $(1,1)$ in Table 3 also show a similar pattern to the results in Table 2 . These results, with the CVs of both $\mathrm{GARCH}(1,1)$ and asymmetric GARCH $(1,1)$, confirm that high(low) retail ISENT undermines (restores) a positive MVR and that the retail ISENT of the individual stock plays an important role in the individual $\mathrm{MVR}^{7}$.

\subsection{Small vs. large capitalization stocks}

Baker and Wurgler (2007) show that the returns of small capitalization stocks are more affected by ISENT in the stock market than the returns of large capitalization stocks, because of high costs of arbitrage (D'Avolio 2002). Kumar and Lee (2006) also report that retail ISENT shifts have more explanatory power for future returns of small capitalization stocks. Motivated by their research, we construct the two-regime retail ISENT equation for small and large capitalization stock returns.

Table 4 reports the results of the regression models for small and large capitalization stock returns with CVs of both GARCH $(1,1)$ and asymmetric GARCH $(1,1)$. Stock $i$ is defined as a small (large) capitalization stock in month $t$ when the capitalization of stock $i$ is smaller (larger) than the median of all individual stocks' capitalizations in month $t$. In column (S1), the coefficient estimate of CV for small capitalization stocks is -0.197 and significant at the $1 \%$ level. On the other hand, the coefficient estimate of CV for large capitalization stocks is 0.370 with a $t$-statistic of 7.32 in column (L1). This implies that the MVR of large capitalization stocks is consistent with the classical finance theories. Baker and Wurgler (2007) argue that small capitalization stocks are likely to be more sensitive to flows of ISENT. Yu (2011) points out that analysts are more interested in large companies than small ones, which also leads to the more interests of institutional investors on large companies. Institutional investors with the large amount of funds also hesitate to invest their funds in small firms because of the

\footnotetext{
${ }^{7}$ We construct a trading strategy based on the findings in this research. For each month, we list up the individual stocks in the CV order. If the BSI of the stock is lower (higher) than the median of BSIs of all individual stocks, we suggest to take a long (short) position in stocks with the high CV. The portfolios are rebalanced at the end of each month.
} 
Table 4. Individual MVR for small and large capitalization stocks

\begin{tabular}{lcccccccc}
\hline & \multicolumn{9}{c}{$\mathrm{GARCH}(1,1)$} & \multicolumn{5}{c}{ Asymmetric GARCH(1,1) } \\
\hline & $(\mathrm{S} 1)$ & $(\mathrm{L} 1)$ & $(\mathrm{S} 2)$ & $(\mathrm{L} 2)$ & $(\mathrm{S} 3)$ & $(\mathrm{L} 3)$ & $(\mathrm{S} 4)$ & $(\mathrm{L} 4)$ \\
\hline Var $_{t}\left(R_{i, t+1}\right)$ & $-0.197^{* * * *}$ & $0.370^{* * *}$ & $-0.127^{* * *}$ & $0.514^{* * *}$ & $-0.201^{* * *}$ & $0.390^{* * *}$ & $-0.131^{* * *}$ & $0.541^{* * *}$ \\
& $(-7.89)$ & $(7.32)$ & $(-3.77)$ & $(6.17)$ & $(-8.08)$ & $(6.84)$ & $(-3.94)$ & $(5.56)$ \\
\hline$D_{i, t} \times$ Var $_{t}\left(R_{i, t+1}\right)$ & & & $-0.175^{* * *}$ & $-0.316^{* * *}$ & & & $-0.175^{* * *}$ & $-0.327^{* * *}$ \\
& & & $(-3.55)$ & $(-3.24)$ & & & $(-3.55)$ & $(-3.00)$ \\
\hline$D_{i, t}$ & & & -0.003 & $0.008^{* * *}$ & & & -0.003 & $0.008^{* * *}$ \\
& & & $(-1.45)$ & $(3.14)$ & & & $(-1.52)$ & $(2.85)$ \\
\hline$R_{m k t, t}-R_{f, t}$ & $0.941^{* * *}$ & $1.057^{* * *}$ & $0.939^{* * *}$ & $1.057^{* * *}$ & $0.941^{* * *}$ & $1.058^{* * *}$ & $0.939^{* * *}$ & $1.057^{* * *}$ \\
& $(98.24)$ & $(88.40)$ & $(98.21)$ & $(88.49)$ & $(98.23)$ & $(88.41)$ & $(98.19)$ & $(88.49)$ \\
\hline HML & $0.308^{* * *}$ & $0.279^{* * *}$ & $0.308^{* * *}$ & $0.279^{* * *}$ & $0.309^{* * *}$ & $0.278^{* * *}$ & $0.308^{* * *}$ & $0.279^{* * *}$ \\
& $(16.25)$ & $(12.46)$ & $(16.19)$ & $(12.51)$ & $(16.25)$ & $(12.48)$ & $(16.19)$ & $(12.55)$ \\
\hline SMB & $1.009^{* * *}$ & $0.788^{* * *}$ & $1.007^{* * *}$ & $0.786^{* * *}$ & $1.009^{* * *}$ & $0.788^{* * *}$ & $1.007^{* * *}$ & $0.787^{* * *}$ \\
& $(58.66)$ & $(33.60)$ & $(58.83)$ & $(33.87)$ & $(58.67)$ & $(33.77)$ & $(58.83)$ & $(34.11)$ \\
\hline Constant & $0.003^{* * *}$ & $0.005^{* * *}$ & $0.003^{* * *}$ & 0.002 & $0.003^{* * *}$ & $0.005^{* * *}$ & $0.003^{* * *}$ & 0.001 \\
& $(3.01)$ & $(3.94)$ & $(2.63)$ & $(0.86)$ & $(3.11)$ & $(3.15)$ & $(2.77)$ & $(0.49)$ \\
\hline Observations & 102974 & 103061 & 102974 & 103061 & 102974 & 103061 & 102974 & 103061 \\
\hline $\mathrm{R}^{2}$ & 0.1433 & 0.1289 & 0.1441 & 0.1295 & 0.1433 & 0.1292 & 0.1442 & 0.1299 \\
\hline
\end{tabular}

Notes: Columns $(\mathrm{S} i)(i=1,2,3,4)$ and $(\mathrm{L} j)(j=1,2,3,4)$ report results for small and large capitalization stocks, respectively. Heteroscedasticity-consistent $t$-statistics are reported in parentheses. ${ }^{* * *}, * *$, and $*$ denote significance at the $1 \%, 5 \%$, and $10 \%$ levels.

liquidity issue. Accordingly, we observe more sentiment driven trading than informed driven trading among small companies. The results with the BSI dummy variable in columns (S2) and (L2) show that large capitalization stocks with high retail ISENT have weaker positive MVR suggested by the classical finance theories than those with low retail ISENT. However, large capitalization stocks with high retail ISENT still sustain the positive MVR. For the CV of asymmetric GARCH $(1,1)$, the pattern of empirical results in columns (S3), (L3), (S4), and (L4) is similar to that for the CV of GARCH $(1,1)$. Table 4 also shows the similar results with Table 3.

\subsection{Low- vs. high-priced stocks}

Kumar and Lee (2006) show that retail investors seem to avoid highly priced stocks. Accordingly, their research suggests that retail ISENT has a stronger effect on lowpriced stocks than on high-priced stocks. Thus, we analyze the effect of retail ISENT on individual MVR for low- and high-priced stocks.

Table 5 presents the results of the two-regime regression models for low- and highpriced stocks. Stock $i$ is defined as low-(high-) priced stock in month $t$ when the price of stock $i$ is lower (higher) than the median of all individual stocks' prices in month $t$. With the CV of GARCH $(1,1)$, low-(high-)priced stock shows a negative(positive) MVR in column (L1)(column (H1)). These results suggest that inexperienced and naive individual investors prefer to trade low-priced stocks because of their small amount of budget. 
Table 5. Individual MVR for low- and high-priced stocks

\begin{tabular}{|c|c|c|c|c|c|c|c|c|}
\hline & \multicolumn{4}{|c|}{$\operatorname{GARCH}(1,1)$} & \multicolumn{4}{|c|}{ Asymmetric GARCH( $(1,1)$} \\
\hline & (L1) & (H1) & (L2) & $(\mathrm{H} 2)$ & (L3) & (H3) & (L4) & (H4) \\
\hline $\operatorname{Var}_{t}\left(R_{i, t+1}\right)$ & $\begin{array}{c}-0.219 * * * \\
(-9.56)\end{array}$ & $\begin{array}{c}0.424 * * * \\
(8.11)\end{array}$ & $\begin{array}{c}-0.208 * * * \\
(-6.87)\end{array}$ & $\begin{array}{c}0.563 * * * \\
(7.19)\end{array}$ & $\begin{array}{c}-0.212 * * * \\
(-8.94)\end{array}$ & $\begin{array}{c}0.432 * * * \\
(7.40)\end{array}$ & $\begin{array}{c}-0.214 * * * \\
(-6.99)\end{array}$ & $\begin{array}{c}0.583 * * * \\
(6.56)\end{array}$ \\
\hline$D_{i, t} \times \operatorname{Var}_{t}\left(R_{i, t+1}\right)$ & & & $\begin{array}{l}-0.017 \\
(-0.37)\end{array}$ & $\begin{array}{c}-0.354 * * * \\
(-3.66)\end{array}$ & & & $\begin{array}{l}0.017 \\
(0.36)\end{array}$ & $\begin{array}{c}-0.390 * * * \\
(-3.73)\end{array}$ \\
\hline$D_{i, t}$ & & & $\begin{array}{c}-0.007 * * * \\
(-3.89)\end{array}$ & $\begin{array}{c}0.011 * * * \\
(4.72)\end{array}$ & & & $\begin{array}{c}-0.008^{* * *} \\
(-4.54)\end{array}$ & $\begin{array}{c}0.012 * * * \\
(4.67)\end{array}$ \\
\hline$R_{m k t, t}-R_{f, t}$ & $\begin{array}{l}1.052 * * * \\
(101.03)\end{array}$ & $\begin{array}{c}0.950 * * * \\
(84.12)\end{array}$ & $\begin{array}{l}1.050 * * * \\
(100.98)\end{array}$ & $\begin{array}{c}0.949 * * * \\
(84.19)\end{array}$ & $\begin{array}{l}1.051 * * * \\
(100.99)\end{array}$ & $\begin{array}{c}0.950 * * * \\
(84.08)\end{array}$ & $\begin{array}{l}1.050 * * * \\
(100.94)\end{array}$ & $\begin{array}{c}0.950 * * * \\
(84.15)\end{array}$ \\
\hline HML & $\begin{array}{c}0.215 * * * \\
(13.21)\end{array}$ & $\begin{array}{c}0.370 * * * \\
(15.26)\end{array}$ & $\begin{array}{c}0.213^{* * * *} \\
(13.08)\end{array}$ & $\begin{array}{c}0.372 * * * \\
(15.34)\end{array}$ & $\begin{array}{c}0.215 * * * \\
(13.21)\end{array}$ & $\begin{array}{c}0.369 * * * \\
(15.26)\end{array}$ & $\begin{array}{c}0.213 * * * \\
(13.06)\end{array}$ & $\begin{array}{c}0.371 * * * \\
(15.36)\end{array}$ \\
\hline SMB & $\begin{array}{c}0.972 * * * \\
(60.86)\end{array}$ & $\begin{array}{c}0.821 * * * \\
(34.03)\end{array}$ & $\begin{array}{c}0.971 * * * \\
(60.85)\end{array}$ & $\begin{array}{c}0.819 * * * \\
(34.35)\end{array}$ & $\begin{array}{c}0.972 * * * \\
(60.84)\end{array}$ & $\begin{array}{c}0.822 * * * \\
(34.24)\end{array}$ & $\begin{array}{c}0.971 * * * \\
(60.85)\end{array}$ & $\begin{array}{c}0.820 * * * \\
(34.64)\end{array}$ \\
\hline Constant & $\begin{array}{c}0.004 * * * \\
(4.18)\end{array}$ & $\begin{array}{c}0.005 * * * \\
(3.44)\end{array}$ & $\begin{array}{c}0.006^{* * * *} \\
(5.28)\end{array}$ & $\begin{array}{l}0.000 \\
(0.19)\end{array}$ & $\begin{array}{c}0.003 * * * \\
(3.62)\end{array}$ & $\begin{array}{c}0.005^{* * *} \\
(3.00)\end{array}$ & $\begin{array}{c}0.006^{* * *} \\
(5.38)\end{array}$ & $\begin{array}{l}-0.000 \\
(-0.01)\end{array}$ \\
\hline Observations & 103029 & 103006 & 103029 & 103006 & 103029 & 103006 & 103029 & 103006 \\
\hline $\mathrm{R}^{2}$ & 0.1527 & 0.1200 & 0.1530 & 0.1208 & 0.1526 & 0.1202 & 0.1530 & 0.1211 \\
\hline
\end{tabular}

Notes: Columns $(\mathrm{L} i)(i=1,2,3,4)$ and $(\mathrm{H} j)(j=1,2,3,4)$ report results for low- and high-priced stocks, respectively. Heteroscedasticity-consistent $t$-statistics are reported in parentheses. ${ }^{* * *}, * *$, and $*$ denote significance at the $1 \%, 5 \%$, and $10 \%$ levels.

Consequently, our findings suggest that low-priced stocks are largely affected by the sentiment traders who under-estimate the MVRs; therefore, we generally find the negative MVR among low-priced stocks. In column (H2), all of the high-priced stocks still sustain the positive MVR, although the high-priced stocks with high retail ISENT have weaker positive MVR than those with low retail ISENT. The results with the CV of asymmetric GARCH $(1,1)$ in columns (L3), (H3), (L4), and (H4) are similar to those with the $\mathrm{CV}$ of GARCH $(1,1)$. These results in Table 5 confirm that the MVR is more affected by retail ISENT for low-priced stock than for high-priced stock and are consistent with the finding in Kumar and Lee (2006).

\subsection{Growth vs. value stocks}

Barber and Odean (2000) find that the average household prefers to take a long position in value stocks rather than growth stocks. Kumar and Lee (2006) also show that the beta of BSI for value stock returns is positive and highly significant at the $1 \%$ level, while the beta of BSI for growth stock returns is insignificant. Their empirical results imply that retail ISENT has a more direct influence on value stock returns than on growth stock returns. In our study, we analyze the individual MVR for growth and value stocks to investigate the effect of retail ISENT on growth and value stock returns. 
Table 6. Individual MVR for growth and value stocks

\begin{tabular}{lcccccccc}
\hline & \multicolumn{3}{c}{$\mathrm{GARCH}(1,1)$} & \multicolumn{5}{c}{ Asymmetric GARCH(1,1) } \\
\hline & $(\mathrm{G} 1)$ & $(\mathrm{V} 1)$ & $(\mathrm{G} 2)$ & $(\mathrm{V} 2)$ & $(\mathrm{G} 3)$ & $(\mathrm{V} 3)$ & $(\mathrm{G} 4)$ & $(\mathrm{V} 4)$ \\
\hline Var $_{t}\left(R_{i, t+1}\right)$ & $0.213^{* * *}$ & $-0.281^{* * *}$ & $0.346^{* * *}$ & $-0.249^{* * *}$ & $0.225^{* * *}$ & $-0.282^{* * *}$ & $0.357^{* * *}$ & $-0.252^{* * * *}$ \\
& $(5.14)$ & $(-11.14)$ & $(5.48)$ & $(-7.21)$ & $(4.87)$ & $(-11.15)$ & $(4.97)$ & $(-7.30)$ \\
\hline$D_{i, t} \times$ Var $_{t}\left(R_{i, t+1}\right)$ & & & $-0.317^{* * *}$ & -0.077 & & & $-0.318^{* * *}$ & -0.071 \\
& & & $(-4.04)$ & $(-1.54)$ & & & $(-3.72)$ & $(-1.42)$ \\
\hline$D_{i, t}$ & & & $0.008^{* * *}$ & -0.001 & & & $0.008^{* * *}$ & -0.002 \\
& & & $(3.21)$ & $(-0.99)$ & & & $(2.90)$ & $(-1.11)$ \\
\hline$R_{m k t, t}-R_{f, t}$ & $1.066^{* * *}$ & $0.931^{* * *}$ & $1.065^{* * *}$ & $0.931^{* * *}$ & $1.066^{* * *}$ & $0.9311^{* * *}$ & $1.065^{* * *}$ & $0.930^{* * *}$ \\
& $(83.41)$ & $(111.42)$ & $(83.45)$ & $(111.34)$ & $(83.40)$ & $(111.42)$ & $(83.43)$ & $(111.35)$ \\
\hline HML & $0.100^{* * *}$ & $0.477^{* * *}$ & $0.101^{* * *}$ & $0.477^{* * *}$ & $0.100^{* * *}$ & $0.478^{* * *}$ & $0.101^{* * *}$ & $0.477^{* * *}$ \\
& $(3.95)$ & $(33.13)$ & $(3.99)$ & $(33.02)$ & $(3.95)$ & $(33.18)$ & $(3.99)$ & $(33.07)$ \\
\hline SMB & $1.017^{* * *}$ & $0.782^{* * *}$ & $1.015^{* * *}$ & $0.781^{* * *}$ & $1.017^{* * *}$ & $0.782^{* * *}$ & $1.016^{* * *}$ & $0.781^{* * *}$ \\
& $(40.23)$ & $(61.94)$ & $(40.49)$ & $(62.10)$ & $(40.41)$ & $(61.87)$ & $(40.73)$ & $(62.04)$ \\
\hline Constant & $0.013^{* * *}$ & 0.001 & $0.009^{* * *}$ & 0.001 & $0.012^{* * *}$ & 0.000 & $0.009^{* * *}$ & 0.001 \\
& $(9.12)$ & $(0.77)$ & $(4.58)$ & $(0.91)$ & $(8.02)$ & $(0.64)$ & $(3.90)$ & $(0.90)$ \\
\hline Observations & 102972 & 103063 & 102972 & 103063 & 102972 & 103063 & 102972 & 103063 \\
\hline $\mathrm{R}^{2}$ & 0.1162 & 0.1760 & 0.1168 & 0.1762 & 0.1163 & 0.1760 & 0.1170 & 0.1762 \\
\hline
\end{tabular}

Notes: Columns $(\mathrm{G} i)(i=1,2,3,4)$ and $(\mathrm{V} j)(j=1,2,3,4)$ report results for growth and value stocks, respectively. Heteroscedasticity-consistent $t$-statistics are reported in parentheses. ${ }^{* * *}, * *$, and $*$ denote significance at the $1 \%, 5 \%$, and $10 \%$ levels.

Table 6 presents results of the regression models for growth and value. Stock $i$ is defined as value (growth) stock in month $t$ when the book-to-market ratio of stock $i$ is higher (lower) than median of all individual stocks' book-to-market ratios in month $t$. The coefficient estimate of CV in column (G1) is 0.213 with a $t$-statistic of 5.14, whereas the coefficient estimate in column (V1) is negative $(-0.281)$ and significant at the $1 \%$ level. In columns (G2), the value stocks are less affected by the retail ISENT than growth stocks that are consistent with Barber and Odean (2008). The coefficient estimates are also economically impressive. For growth stocks with high-sentiment, a one-standarddeviation increase in GARCH (asymmetric GARCH) is associated with an increase of 0.001047 (0.001349) in monthly individual stock excess returns. Consequently, the results suggest that the positive coefficient of the CV in column (G1) is mostly driven by the effect of the low-sentiment firms. However, column (V2) shows the insignificant coefficient of the interaction term between the $\mathrm{CV}$ and the sentiment dummy and the negatively significant coefficient of the CV. This implies that value firms consistently have a negative risk-return relation among high- and low-sentiment firms. As shown in Tables $2-5$, the results with the $\mathrm{CV}$ estimated by asymmetric $\operatorname{GARCH}(1,1)$ in columns (G3), (V3), (G4), and (V4) are similar to the results with the CV of GARCH $(1,1)$. Our results indicate that because of retail investors, positive individual MVRs are more undetectable for value stocks than growth stocks. 


\section{Conclusions}

ISENT plays an important role in determining future stock returns when individual investors participate in stocks aggressively. Classical models in finance posit a positive risk-return relation suggesting that high risk is compensated by high rewards, although empirical studies find mixed results. In this research, we try to shed some light on the literature by considering stock-level ISENT. In this regard, we find that a negative MVR is observed only among high-sentiment stocks. On the other hand, we observe a positive MVR among low-sentiment stocks, which is consistent with the intuition of classical theoretical models. Our study is particularly meaningful because prior studies focus only on time-varying market-wide ISENT, but we further consider the cross-sectional variation of stock-level ISENT among individual stocks. Additionally, we provide evidence that stock-level ISENT has a strong effect on the individual MVR among stocks with high retail investor concentration (e.g., small capitalization, low-priced, and value stocks). Our results suggest that ISENT for individual stocks captures valuable information on the risk-return trade-off and that the characteristic of an individual stock is related to the effect of its ISENT. The dynamics of BSI captures turbulent ISENT during the financial crisis. They also suggest that the ISENT collapses in 2008 because of the financial crisis. However, the level of BSI recovers in 2009, indicating that the financial crisis does not affect the ISENT for a long time in Korean stock market. We conjecture that the level of BSI recovers relatively quickly, because of the weak relation between the financial crisis and the fundamental of Korean stock market. Our research has some limitations. For instance, D'Avolio (2002) utilizes the level of institutional ownership as short-selling constraints. Further, he also expects that the institutional ownership has an impact on the ISENT. However, our research does not reflect the ownership level of retail, institutional, and foreign investors because the ownership level data are not publicly available. Therefore, we look forward to overcoming the limitation in the future research.

\section{Acknowledgments}

The authors are grateful for the helpful comments and suggestions from Suk Joon Byun, Inmoo Lee, and Jun-Koo Kang. This work was supported by the Incheon National University Research Grant in 2015.

\section{References}

Abad, P.; Robles, M. D. 2014. Credit rating agencies and idiosyncratic risk: is there a linkage? Evidence from the Spanish market, International Review of Economics \& Finance 33: 152-171. https://doi.org/10.1016/j.iref.2014.05.002

Antoniou, C.; Doukas, J. A.; Subrahmanyam, A. 2016. Investor sentiment, beta, and the cost of equity capital, Management Science 62(2): 347-367. https://doi.org/10.1287/mnsc.2014.2101

Baker, M.; Wurgler, J. 2006. Investor sentiment and the cross-section of stock returns, Journal of Finance 61(4): 1645-1680. https://doi.org/10.1111/j.1540-6261.2006.00885.x

Baker, M.; Wurgler, J. 2007. Investor sentiment in the stock market, Journal of Economic Perspectives 21(2): 129-151. https://doi.org/10.1257/jep.21.2.129 
Baker, M.; Wurgler, J.; Yuan, Y. 2012. Global, local, and contagious investor sentiment, Journal of Financial Economics 104(2): 272-287. https://doi.org/10.1016/j.jfineco.2011.11.002

Barber, B. M.; Odean, T. 2000. Trading is hazardous to your wealth: the common stock investment performance of individual investors, Journal of Finance 55(2): 773-806.

https://doi.org/10.1111/0022-1082.00226

Barber, B. M.; Odean, T. 2008. All that glitters: the effect of attention and news on the buying behavior of individual and institutional investors, Review of Financial Studies 21(2): 785-818. https://doi.org/10.1093/rfs/hhm079

Becker, R.; Clements, A. E.; McClelland, A. 2009. The jump component of S\&P 500 volatility and the VIX index, Journal of Banking \& Finance 33(6): 1033-1038.

https://doi.org/10.1016/j.jbankfin.2008.10.015

Bollerslev, T. 1986. Generalized autoregressive conditional heteroscedasticity, Journal of Econometrics 31(3): 307-328. https://doi.org/10.1016/0304-4076(86)90063-1

Brandt, M. W.; Kang, Q. 2004. On the relationship between the conditional mean and volatility of stock returns: a latent VAR approach, Journal of Financial Economics 72(2): 217-257.

https://doi.org/10.1016/j.jfineco.2002.06.001

Campbell, J. Y.; Cochrane, J. H. 1999. By force of habit: a consumption-based explanation of aggregate stock market behavior, Journal of Political Economy 107(2): 205-251.

https://doi.org/10.1086/250059

Corsi, F. 2009. A simple approximate long-memory model of realized volatility, Journal of Financial Econometrics 7(2): 174-196. https://doi.org/10.1093/jjfinec/nbp001

Da, Z.; Engelberg, J.; Gao, P. 2015. The sum of all fears investor sentiment and asset prices, Review of Financial Studies 28(1): 1-32. https://doi.org/10.1093/rfs/hhu072

Danbolt, J.; Siganos, A.; Vagenas-Nanos, E. 2015. Investor sentiment and bidder announcement abnormal returns, Journal of Corporate Finance 33: 164-179.

https://doi.org/10.1016/j.jcorpfin.2015.06.003

D'Avolio, G. 2002. The market for borrowing stock, Journal of Financial Economics 66(2-3): 271-306. https://doi.org/10.1016/S0304-405X(02)00206-4

Engle, R. 2001. GARCH 101: the use of ARCH/GARCH models in applied econometrics, Journal of Economic Perspectives 15(4): 157-168. https://doi.org/10.1257/jep.15.4.157

Fama, E. F.; French, K. R. 1989. Business conditions and expected returns on stocks and bonds, Journal of Financial Economics 25(1): 23-49. https://doi.org/10.1016/0304-405X(89)90095-0

Fama, E. F.; French, K. R. 1992. The cross-section of expected stock returns, Journal of Finance 47(2): 427-465. https://doi.org/10.1111/j.1540-6261.1992.tb04398.x

Ghysels, E.; Guérin, P.; Marcellino, M. 2014. Regime switches in the risk-return trade-off, Journal of Empirical Finance 28: 118-138. https://doi.org/10.1016/j.jempfin.2014.06.007

Glosten, L. R.; Jagannathan, R.; Runkle, D. E. 1993. On the relation between the expected value and the volatility of the nominal excess return on stocks, Journal of Finance 48(5): 1779-1801. https://doi.org/10.1111/j.1540-6261.1993.tb05128.x

Ho, C.; Hung, C.-H. 2009. Investor sentiment as conditioning information in asset pricing, Journal of Banking \& Finance 33(5): 892-903. https://doi.org/10.1016/j.jbankfin.2008.10.004

Hong, G.; Lee, B. S. 2011. The trading behavior and price impact of foreign, institutional, individual investors and government: evidence from Korean equity market, Japan and the World Economy 23(4): 273-287. https://doi.org/10.1016/j.japwor.2011.10.002

Karlsson, N.; Loewenstein, G.; Seppi, D. 2009. The ostrich effect: selective attention to information, Journal of Risk and Uncertainty 38(2): 95-115. https://doi.org/10.1007/s11166-009-9060-6 
Kinnunen, J. 2014. Risk-return trade-off and serial correlation: do volume and volatility matter?, Journal of Financial Markets 20: 1-19. https://doi.org/10.1016/j.finmar.2014.04.003

Kumar, A.; Lee, C. M. C. 2006. Retail investor sentiment and return comovements, Journal of Finance 61(5): 2451-2486. https://doi.org/10.1111/j.1540-6261.2006.01063.x

Li, Q.; Yang, J.; Hsiao, C.; Chang, Y.-J. 2005. The relationship between stock returns and volatility in international stock markets, Journal of Empirical Finance 12(5): 650-665.

https://doi.org/10.1016/j.jempfin.2005.03.001

Lettau, M.; Ludvigson, S. C. 2010. Measuring and modeling variation in the risk-return tradeoff, in Y. Ait-Shalia, L. Hansen (Eds.). Handbook of Financial Econometrics. North Holland, Amsterdam: Elsevier Science B.V., 617-690. https://doi.org/10.1016/B978-0-444-50897-3.50014-6

Massa, M.; Yadav, V. 2015. Investor sentiment and mutual fund strategies, Journal of Financial and Quantitative Analysis 50(4): 699-727. https://doi.org/10.1017/S0022109015000253

Merton, R. C. 1980. On estimating the expected return on the market: an exploratory investigation, Journal of Financial Economics 8(4): 323-361. https://doi.org/10.1016/0304-405X(80)90007-0

Odean, T. 1998. Are investors reluctant to realize their losses?, Journal of Finance 53(5): 17751798. https://doi.org/10.1111/0022-1082.00072

Shen, J.; Yu, J.; Zhao, S. 2016. Investor sentiment and economic forces [online], [cited 9 October 2016]. Available from Internet: http://ssrn.com/abstract=1991244

Stambaugh, R. F.; Yu, J.; Yuan, Y. 2012. The short of it: investor sentiment and anomalies, Journal of Financial Economics 104(2): 288-302. https://doi.org/10.1016/j.jineco.2011.12.001

Yu, J. 2011. Disagreement and return predictability of stock portfolios, Journal of Financial Economics 99(1): 162-183. https://doi.org/10.1016/j.jfineco.2010.08.004

Yu, J.; Yuan, Y. 2011. Investor sentiment and the mean-variance relation, Journal of Financial Economics 100(2): 367-381. https://doi.org/10.1016/j.jfineco.2010.10.011

Jun Sik KIM is an Assistant Professor in the Division of International Trade at Incheon National University. His research interests cover the areas of volatility forecasting, behavioral finance, and empirical asset pricing.

Da-Hea KIM is an Assistant Professor in SKK Business School, Sungkyunkwan University. Her research interests cover the areas of empirical asset pricing, derivatives, and behavioral finance.

Sung Won SEO is an Assistant Professor in School of Business at Ajou University. He is interested in the areas of behavioral finance, empirical asset pricing, and corporate finance. 